\title{
BMJ Open Complex care for kids Ontario: protocol for a mixed-methods randomised controlled trial of a population-level care coordination initiative for children with medical complexity
}

\author{
Julia Orkin, ${ }^{1,2}$ Carol Y Chan, ${ }^{3}$ Nora Fayed, ${ }^{4}$ Jia Lu Lilian Lin, ${ }^{5}$ Nathalie Major, ${ }^{6}$ \\ Audrey Lim, ${ }^{7}$ Erin R Peebles, ${ }^{8}$ Myla E Moretti, ${ }^{9}$ Joanna Soscia,${ }^{1}$ Roxana Sultan, ${ }^{10}$ \\ Andrew R Willan, ${ }^{9}$ Martin Offringa, ${ }^{3}$ Astrid Guttmann, ${ }^{1,11}$ Leah Bartlett, ${ }^{12}$ \\ Ronik Kanani, ${ }^{13}$ Erin Culbert, ${ }^{14}$ Karolyn Hardy-Brown, ${ }^{15}$ Michelle Gordon, ${ }^{16}$ \\ Marty Perlmutar, ${ }^{17}$ Eyal Cohen ${ }^{1,2}$
}

To cite: Orkin J, Chan CY, Fayed N, et al. Complex care for kids Ontario: protocol for a mixed-methods randomised controlled trial of a populationlevel care coordination initiative for children with medical complexity. BMJ Open 2019:9:e028121. doi:10.1136/ bmjopen-2018-028121

- Prepublication and additional material is published online only. To view please visit the journal online (http://dx.doi.org/10. 1136/bmjopen-2018-028121).

Received 22 November 2018 Revised 20 March 2019 Accepted 24 May 2019

Check for updates

(c) Author(s) (or their employer(s)) 2019. Re-use permitted under CC BY-NC. No commercial re-use. See rights and permissions. Published by BMJ.

For numbered affiliations see end of article.

Correspondence to

Dr. Julia Orkin;

julia.orkin@sickkids.ca

\section{ABSTRACT}

Introduction Technological and medical advances have led to a growing population of children with medical complexity (CMC) defined by substantial medical needs, healthcare utilisation and morbidity. These children are at a high risk of missed, fragmented and/or inappropriate care, and families bear extraordinary financial burden and stress. While small in number ( $<1 \%$ of children), this group uses $\sim 1 / 3$ of all child healthcare resources, and need coordinated care to optimise their health. Complex care for kids Ontario (CCKO) brings researchers, families and healthcare providers together to develop, implement and evaluate a population-level roll-out of care for CMC in Ontario, Canada through a randomised controlled trial (RCT) design. The intervention includes dedicated key workers and the utilisation of coordinated shared care plans.

Methods and analysis Our primary objective is to evaluate the CCKO intervention using a randomised waitlist control design. The waitlist approach involves rolling out an intervention over time, whereby all participants are randomised into two groups ( $A$ and $B$ ) to receive the intervention at different time points determined at random. Baseline measurements are collected at month 0 , and groups $A$ and $B$ are compared at months 6 and 12. The primary outcome is the family-prioritized Family Experiences with Coordination of Care (FECC) survey at 12 months. The FECC will be compared between groups using an analysis of covariance with the corresponding baseline score as the covariate. Secondary outcomes include reports of child and parent health outcomes, health system utilisation and process outcomes.

Ethics and dissemination Research ethics approval has been obtained for this multicentre RCT. This trial will assess the effect of a large population-level complex care intervention to determine whether dedicated key workers and coordinated care plans have an impact on improving service delivery and quality of life for $\mathrm{CMC}$ and their families.

Trial registration number NCT02928757.
Strengths and limitations of this study

This is the first large population-level implementation and mixed-methods evaluation assessing the effectiveness of a complex care programme for children with medical complexity (complex care for kids Ontario)

- The study cohort represents a diverse sample of complex care patients across Ontario and the utilisation of broad outcomes that encompass multiple potential targets of care with parent codevelopment in terms of the selection of outcome measures used.

- A limitation of this study relates to the challenge of the patient population as many are too unwell to be safely randomised to a waitlist design and therefore are excluded from the study. However, we will be able to use routinely collected health administrative data to describe heathcare utilisation as a single outcome for this population as to not lose the significance of their data.

\section{INTRODUCTION}

Medical advances have led to improved survival for many previously life-threatening conditions of childhood, such as prematurity, ${ }^{1}$ congenital anomalies ${ }^{2}$ and congenital or acquired brain injury. ${ }^{3}$ Technological advances such as ventilator support, feeding tubes and transplantation have successfully prolonged the lives of children with lung, gut and other organ failure. This epidemiological transition ${ }^{4}$ has created a burgeoning population of children with medical complexity (CMC) — children with new morbidities, which are caused by longer survival itself as well as the complications of their life-sustaining therapies and created a 
new population that requires specialised care delivery to meet their complex healthcare needs.

CMC have been defined as "children with chronic conditions with elevated service needs, functional limitations and high healthcare utilisation, ${ }^{5}$ Data from Ontario, Canada suggest that while CMC account for $\sim 0.7 \%$ of all children, they use about one-third of all child health resources. ${ }^{6}$ Studies from the USA have also reported that CMC account for $43 \%$ of child deaths, $49 \%$ of hospital days and $75 \%-92 \%$ of consumed assistive health technology. ${ }^{7}$ CMC and their parental caregivers endure enormous challenges, including multiple and prolonged hospitalisations, ${ }^{9}$ frequent medical errors, ${ }^{10}$ poor care coordination $^{911}$ and extraordinary stress. ${ }^{12}$ The consequences may include poor caregiver health, ${ }^{13}$ marital strain $^{14}$ and profound negative financial impact. ${ }^{15}$

Previous research has shown through a series of before and after studies, that targeted and integrated complex care interventions, most commonly within structured clinical programme, may improve the health outcomes of $\mathrm{CMC}^{16}{ }^{16}$ including reducing the burden of caregiving, ${ }^{17}$ and mitigating costly and unnecessary healthcare expenditures. ${ }^{18} 19$ Other studies have shown additional benefits such as a decreased need for medical information and improved satisfaction, ${ }^{20}$ improved family perceptions of their providers, their overall healthcare experience and provider communication, ${ }^{21}$ as well as decreased unplanned healthcare visits. ${ }^{22}$ However, the validity of these findings has been limited by small sample sizes, lack of control groups and incomplete outcome measures. ${ }^{23}$ Published randomised controlled trials (RCTs) report improved parental satisfaction with care, but mixed results for other outcomes. One parallel-group RCT described a decrease in both rates of severe illness and healthcare costs ${ }^{24}$ among children enrolled in a structured complex care programme, while another cluster RCT reported increased costs with no change in functional status or hospital-based utilisation. ${ }^{25}$

The Provincial Council of Maternal and Child Health $(\mathrm{PCMCH})$ is a provincial organisation, supported by Ontario's public single-payer of healthcare (the Ministry of Health and Long-Term Care). PCMCH implemented complex care kids Ontario (CCKO), a population-health strategy to improve care for CMC by providing an integrated approach to medical care and coordination. The strategy aims to improve service delivery, health and quality of life of the patient families involved through care coordination across acute and primary care, rehabilitation, home and community care, facilitated by dedicated nurse practitioners, ${ }^{26}{ }^{27}$ who function as key workers to establish seamless integrated care through the development and maintenance of a single, comprehensive and collaborative care plan, that is, designed to meet the child's/family's goals and optimise health outcomes (see online supplementary appendix 1 ). The aim of this study is to compare the effectiveness of the CCKO intervention to usual care for CMC in Ontario.
METHODS/DESIGN

\section{Design}

CCKO will utilise a waitlist variation of an RCT design (figure 1). The waitlist approach involves rolling out an intervention over time, whereby all participants are randomised into two groups (A and $\mathrm{B}$ ) to receive the intervention at different time points determined at random. ${ }^{25}{ }^{28}$ Group A receives the intervention at the next available appointment. Group B is placed on a waitlist and receives the intervention after 12 months. This study design uses the time period before the intervention as the control period/baseline, to be compared with those receiving the intervention. ${ }^{29}$ Baseline measurements would be collected at month 0 , and groups $\mathrm{A}$ and B would be compared at months 6 and 12 .

The waitlist design is used in scenarios where it is considered unethical to withhold an intervention with likely benefits, or if there are logistical or financial constraints that prevent the intervention from being administered in whole at one time point. ${ }^{28} 29$ This design generates robust evidence of an intervention programme's effectiveness by leveraging real-world operational need for a staggered rollout. For CCKO, it is logistically not feasible for all eligible children to be seen immediately. For example, the initial intake process for key workers is time intense, requiring the creation of careplans and the development of a patient-provider relationship. A staggered rollout facilitates workflow, allowing programme implementation within the context of human resource limitations. With the exception of patients for whom care coordination is thought to be urgently required (see exclusion criteria (a)-(c)), all patients referred to CCKO will be randomly assigned to either receive the intervention immediately or after the waitlist period (12 months). This approach minimises the risk of selection bias by retaining the design element of randomisation.

\section{Setting}

CCKO will be led by four tertiary care children's hospitals with partnership at multiple community led clinics (see online supplementary appendix 2). These sites display broad geographical representation of patients.

\section{Participants}

The target population includes children in Ontario who satisfy the standard operational definition for CMC developed by PCMCH. ${ }^{30}$ The inclusion criteria are summarised in figure 2. The criteria adapt existing definitions of $\mathrm{CMC}^{5}$ to a slightly narrower group with technology dependence and/or medical fragility to focus on those patients who are most expected to benefit from care coordination such as those thought to be at risk of avoidable hospitalisations.

\section{Exclusion criteria}

a. High utilisation of hospital level care.

- $\geq 3$ hospitalisations, $\geq 2$ intensive care unit admissions, $\geq 30$ days of total hospitalisation in previous 3 months, excluding newborn admission. 


\section{COMPLEX CARE REFERRAL TRIAGE}

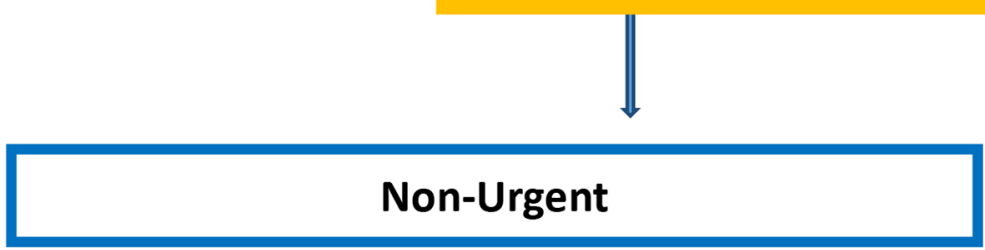

Letter sent to parents with randomly assigned date of clinic appointment (next available or in 12 months) + study invitation letter
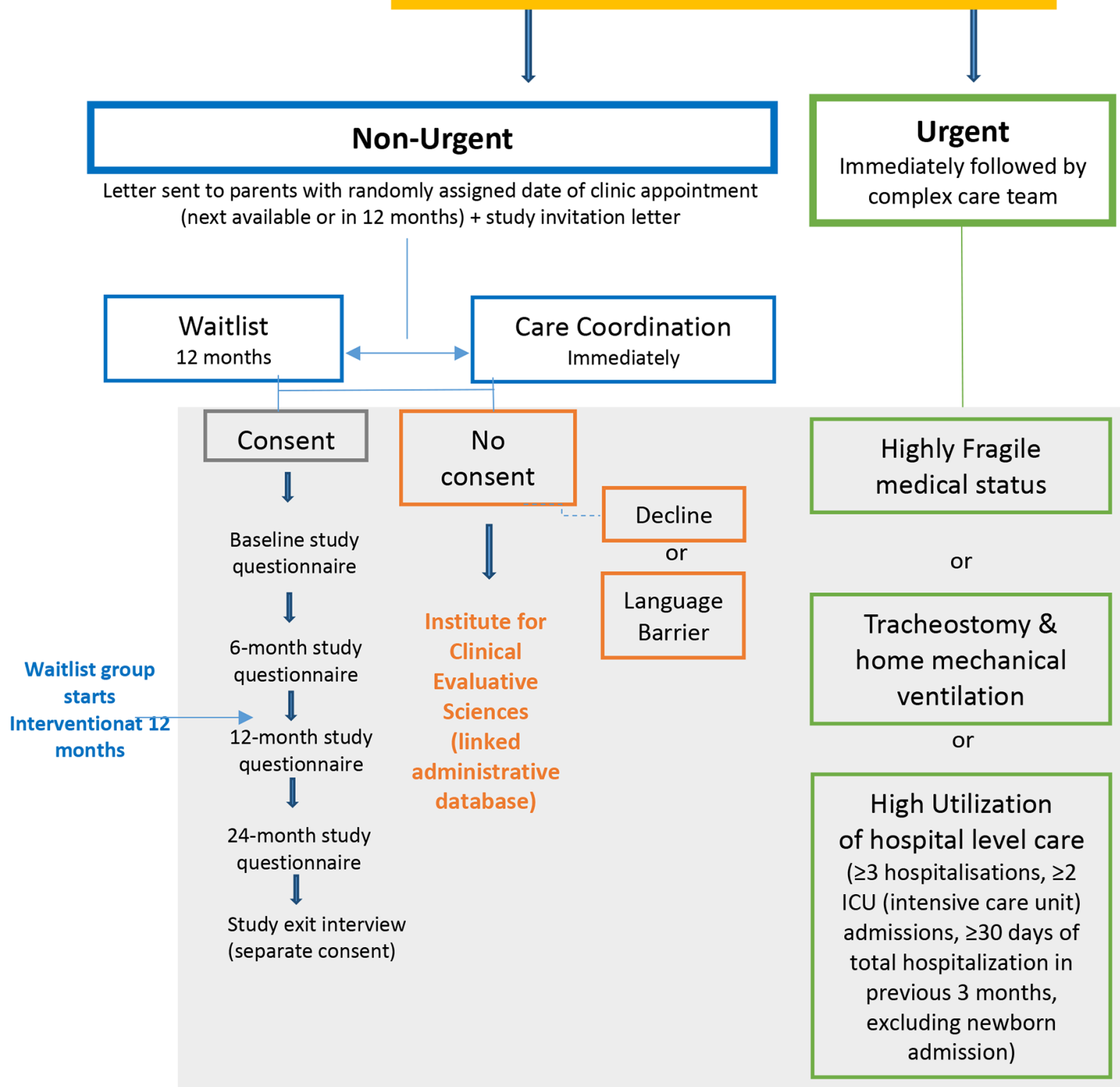

Figure 1 Complex care for kids Ontario evaluation flowchart for referrals.

b. Tracheostomy and home ventilation.

c. Medical status is deemed highly fragile and the need for close follow-up is essential by both referring and triaging team.

d. Already followed by a complex care team.

e. $>16.0$ years of age.

f. Inadequate English proficiency to comprehend study questionnaires.

g. Parent will not be involved in child's care over entirety of study (2 years).

Patients who satisfy exclusion criteria (a)-(c) are deemed to urgently require care coordination; as such, it would be unethical to randomise these patients to a waitlist. Patients who satisfy exclusion criteria (d) would have experienced the potential benefits of care coordination already. Patients who satisfy exclusion criteria (e) would be in the process of being transitioned to adult care. Patients who satisfy exclusion criteria (f) would not be able to complete the study questionnaires as the majority are only validated in English. Patients who satisfy exclusion criteria $(\mathrm{g})$ would not be able to complete the study questionnaires at all time points as these children are placed in out of home care during the study period (social history is provided to the triaging team in each referral).

Patients whose caregivers cannot complete questionnaires in English will not be involved in the primary analysis; however, they will be enrolled in CCKO and provide healthcare utilisation data via health card linkages to health administrative data housed at the Institute for Clinical Evaluative Sciences that will be used in secondary analyses. Similarly, patients who require urgent 


\section{CCKO Standard Operational Definition for Children with Medical Complexity who are Medically Fragile and/or Technology Dependent} Complex Care KIds Ontario

Under 18 years of age and meets at least one criterion from $\mathrm{EACH}$ of the following four conditions:

Technology Dependent and/or users of High Intensity Care

DChild is dependent on mechanical ventilators, and/or requires prolonged intravenous administration of nutritional substances or drugs and/or is expected to have prolonged dependence on other device-based support. For example: tracheostomy tube care/ artificial airway, suctioning, oxygen support or tube feeding.

UChild has prolonged dependence on medical devices to compensate for vital bodily functions, and requires daily/near daily nursing care, eg, cardiorespiratory monitors; renal dialysis due to kidney failure

DChild has any chronic condition that requires great level of care such as: Children who are completely physically dependent on others for activities of daily living (at an age when they would not otherwise be so dependent), Children who require constant medical or nursing supervision or monitoring, medication administration and/or the quantity of medication and therapy they receive. and

$$
\text { Fragility }
$$

and

Chronicity

and

Complexity

Figure 2 Complex care for kids Ontario inclusion criteria.

care coordination are excluded from the study, but will be able to contribute data through similar linkages.

The CCKO intervention involves care coordination, defined as: 'deliberate organization of patient care activities between two or more participants to facilitate the appropriate delivery of health care services. Organizing care involves the marshaling of personnel and other resources needed to carry out required care activities and is often managed by the exchange of information among participants responsible for different aspects of care ' R Mangione-Smith, personal communication, 2016. ${ }^{31}$ Within CCKO, care coordination will include family/healthcare provider cocreation and management of care coordination plans which will be facilitated and accounted for by key workers partnering with families. The key worker would have an advanced practice nursing (eg, nurse practitioner) background and will support the development and enactment of the coordinated care plan between acute care, primary care, rehabilitation, home and community care. Further details about care plan development are available online. ${ }^{32}$ The key worker would be available to provide advice from Monday to Friday, 09:00 to 17:00, and will also develop plans of care for emergencies after hours as part of care plan development. Resources to maintain intervention fidelity among key workers will be maintained with oversight by PCMCH.

The waitlist group consists of CMC who are receiving care from primary and specialty providers, and are waitlisted for complex care clinic (preenrolment control period). Standard of care during the control period will involve care delivered through a primary care provider (family physician or paediatrician) for routine healthcare such as vaccination and acute care visits with subspecialty consultation as needed. Currently, this model of care for the vast majority of CMC in Ontario; among 6200 patients who are estimated to meet CCKO criteria in Ontario, only $\sim 500$ receive care in a structured complex care clinic. At the end of year 1, all CMC randomised to the waitlist will be enrolled in complex care and data will continue to be collected for one additional year on all participants in an extension phase.

Criteria for discontinuing study intervention: participants in the waitlisted arm that experience a change in clinical status and now meet exclusion criteria (eg, prolonged hospital stay $>30$ days), will be taken out of the waitlist arm and will be seen at the next available appointment.

\section{Patient and public involvement}

A family engagement strategy was conducted to identify and prioritise outcomes for evaluation. The core set of relevant patient-reported outcome measures (PROMs) and patient-reported experience measures was created in a consensus meeting using data collected from a survey completed by 48 families and 86 healthcare providers. ${ }^{33}$

\section{Outcomes}

Measures representing these outcomes were selected based on their content applicability to the outcomes, proven psychometric performance (reliability and validity) among 
children and families. The family engagement evaluation framework includes general and specific outcomes within the domains of service delivery (primary and secondary outcomes), child outcomes (secondary) and parent outcomes (secondary).

\section{Primary outcome}

1. Coordination of care among health providers and families.

2. Coordination of care between health providers and families.

3. Utility of follow-up planning tools.

These outcomes will be assessed with the family experiences with coordination of care (FECC) survey, as the primary outcome measure. ${ }^{34}$ The FECC has been validated in a study of 1209 CMC patient families in the USA, and has internal consistency $>0.7$ with proven discriminant validity for patient-family socioeconomic status and rurality ${ }^{36}$ as well as responsiveness to change demonstrated in a recent CMC longitudinal cohort study, R MangioneSmith, personal communication, 2016.

The FECC is composed of 20 separate indicators. Indicators within the FECC that map onto the family-prioritized outcomes (Coordination of Care Among Providers and Families; Coordination of Care Between Providers and Families; and, Care Planning Tools) will be assessed together as the primary study outcome.

Individual FECC indicators will be assessed as secondary outcomes. Among the FECG indicators, 3 indicators will not be collected (FECC 15, 19 and 20) as they hadve content relating to: electronic health records (FECC-19 and 20), which are not universally available in the region of the CCKO intervention; and translation services (FECC 15), which are less relevant in a study population limited to English-speakers.
Child-focused (secondary) outcomes

1. Quality of life and overall emotional health (see table 1).

2. Child's physical pain.

Children's quality of life and emotional well-being will be measured using the WHO definition focused on subjective life appraisal ${ }^{37}$ and a positive orientation of mood assessment, respectively. These outcomes will be assessed using the Feelings subscale from the KIDSCREEN-52 (six items), used in over 250 studies in the child health services literature since its publication in $2005^{38} 39$; and represents the most suitable content overlap with CMC. Children's physical pain will be measured using proxy reports of pain according to a $10 \mathrm{~cm}$ linear Visual Analogue Scale (VAS). ${ }^{40}$ Linear VAS is considered superior to other pain reports available for children due to consistencies of interpretation within parent-child dyads, test-retest reliability and measurement precision, ${ }^{41}$ and is most appropriate for the diverse functional ability of CMC.

\section{Parent-focused (secondary) outcomes}

1. Parents' quality of life.

2. Perceived emotional and physical health.

3. Energy and fatigue.

4. Effects of child's condition on parents' finances and ability to work.

Parents' quality of life will be measured by a subjective life appraisal definition with two scales. (1) Diener's Satisfaction with Life Scale (SWLS) (five items) which is the most validated life satisfaction scale for adults in the health and social sciences literature ${ }^{4243}$ and (2) an adapted KIDSCREEN Feelings subscale, which will allow for direct comparisons of child versus parent life satisfaction. ${ }^{38}$ Parents' perceived health, energy and fatigue will be assessed with short forms

Table 1 Overview of outcomes and associated measures

\section{Service delivery outcomes (measurement tool)}

Coordination among providers (family experiences with care coordination)

Coordination between providers and families (family experiences with care coordination)

Utility of planning/follow-up tools (family experiences with care coordination)

Individual family experiences with care coordination indicators (family experiences with care coordination)

\section{Parent outcomes (measurement tool)}

Life satisfaction (KIDSCREEN, Satisfaction with Life Scale)

Overall health (patientreported outcomes measurement information system)

Energy and fatigue (patient-reported outcomes measurement information system)

Out-of-pocket expenses (expense diary-see online supplementary appendix 3)

Parental support in the community (family experiences with care coordination).

Child outcomes (measurement tool)

Life satisfaction (KIDSCREEN)

Physical pain (Visual Analogue Scale)

(available for all

Health System outcomes (measurement tool)

Health utilisation, for example, hospital admissions, ER visits and so on

Ontario residents in linked administrative databases housed at the Institute for Clinical Evaluative Sciences-see online supplementary appendix 4 for list of databases)
Process outcomes (measurement tool)

Patient and family experience (qualitative interviews) 
of the patient-reported outcomes measurement information system general health (10 items); sleep (8 items); and fatigue ( 8 items) scales. These scales have been validated, have norm references data for comparison and have shown good to excellent psychometric properties among caregivers. ${ }^{44}$ Financial impact on parents' will be measured using an expense diary survey created by the study team. This survey will capture financial impact based on lost time and ability to work, as well as out-of-pocket expenses for healthcare services, equipment and travel using scales customised for CMC and standardised relative to various child health studies with the support of the study health economist (Moretti; see online supplementary appendix 3).

\section{Health system (secondary) outcomes}

A cost-effectiveness analysis will be performed to estimate the incremental costs (or savings) of the CCKO initiative compared with standard care in reducing hospitalisation. Both a healthcare system and societal perspective will be used with a time horizon of 12 months. Cost-effectiveness will be expressed as an incremental cost-effectiveness ratio, calculated by dividing the incremental costs of the intervention by the incremental difference in hospitalisations during the study period. Direct healthcare costs will include cost of the CCKO intervention and health services use by participants during the 12-month period. Indirect costs include caregiver lost productivity measured by participant survey. Health services use by participants will be obtained by linkage to administrative data housed at the Institute for Clinical Evaluative Sciences (ICKES) for consenting participants (see online supplementary appendix 4 for list of datasets). ICES is a not-for-profit research institute listed in Ontario's health privacy legislation as a prescribed entity allowing the use of health data on all Ontario residents for the purposes of research. These datasets will be linked using unique encoded identifiers and analysed at ICESS. Additional health services use covered by third-party payers and parent out-of-pocket expenses will be obtained through surveys.

\section{Sample size}

We determine the sample size to be 140 (70/arm) based on the following criteria: (1) two-sided test of the null hypothesis at the 5\% level; (2) power of $80 \%$; (3) $10 \%$ lost-to-follow-up; projected smallest clinically important difference of 0.5 of the within-patient $\mathrm{SD} .{ }^{46}$

The within-patient SD is needed to obtain a baseline measure from the waitlisted group as reference. The SD of the primary outcome, $\mathrm{FECC}=0.56$ is based on pooled data from the developer's CMC validation sample. ${ }^{36}$ The required sample size is considered feasible as it is estimated that a pool of about 250 patients are readily identifiable for recruitment at CCKO sites.

\section{Recruitment}

At each site, clinical staff will refereligible patients to CCKO. The triaging team will use the inclusion and exclusion criteria to determine eligibility for CCKO and suitability for the research study. A study information letter will be sent to the families of eligible patients who will subsequently be contacted by the research assistant by telephone. The research assistant will explain the research study to the families and obtain informed consent. An approximate $50 \%$ recruitment rate from a pool of $n=400$ (200/year) is conservatively estimated based on previous recruitment and current waitlists.

Questionnaires would take place at baseline, 6, 12 and 24 months. On completion of each time point, families will receive a $\$ 20$ gift card to a drug store. A subsample of 10-15 parents in the intervention arm will be approached 12 months for qualitative interviewing to explore their experience with the intervention.

\section{Randomisation}

CCKO randomisation will be done using a computer-generated algorithm stratified by centre. Blocking will be used to ensure that the two groups are the same size throughout the trial for each site as well as for the trial as a whole. An allocation ratio of $1: 1$ with random block sizes between 6 and 8 will be used within each stratum (centre). This will help to ensure that clinicians or investigators will not decipher the block size.

\section{Data collection}

On obtaining consent, the research assistant will assign a research subject ID number to patients. Study data will be collected and managed using Research Electronic Data Capture (REDCap). ${ }^{47}$ Patient families can opt to complete data collection by iPads or hardcopy. At home, patient families can complete surveys via REDCap. This flexible methods of data collection will maximise diversity of respondents ideally as well as support family needs and preferences for data collection. A demographics survey will be administered at baseline (see online supplementary appendix 5 for demographic questions).

\section{Data management}

A REDCap study database will be designed and maintained by the research coordinator at The Hospital for Sick Children. The data on the various forms will be linked by a unique research subject ID. The research coordinator will extract study data from questionnaires via the REDCap interface to complete the study-specific data collection forms. An external user interface will also be created on REDCap for parents who opt to complete the surveys online.

All personal identifying information will be removed from the electronic study database. A separate secure list of research subjects' names and contact information will be maintained in a Microsoft Excel spreadsheet for the purpose of completing the follow-up questionnaires. All study-related electronic data files will be password-protected and reside on the hospital server. Only members of the research team will have access to the server study file location via password-protected computers. Password-protected databases from each 
site will be transferred to the IC/ES through a Virtual Private Network.

\section{Statistical analysis}

An overview of outcomes are presented in table 1.

\section{Patient and caregiver characteristics}

Baseline patient characteristics and descriptive variables will be presented for each arm: age, sex, diagnosis, ethnicity, medications, medical devices and hospitalisations (see online supplementary appendix 6 for baseline clinical information form). Baseline caregiver characteristics and descriptive variables will be presented as well: age, sex, education level, employment status, ethnicity and primary language. For continuous variables, means and SD or medians (IQR) will be presented. For categorical variables, proportions will be presented.

\section{Primary outcome}

The primary analysis will be a comparison of the priortized service delivery outcomes (ie, Coordination of Care Among Health Providers and Families, Coordination of Care Between Health Providers and Families, Utility of Follow-Up Planning Tools) as measured with the FECC between the intervention and waitlist groups at 12 months. The individual items on the FECC that map most directly to the prioritized outcomes will be utilized for the purpose of the primary outcome analysis. The principle of intention-to-treat will be applied. For effectiveness each outcome variable at month 12 will be compared between groups using an analysis of covariance with the corresponding baseline score as the covariate. A two-sided, level 0.05 test of hypothesis will be applied.

\section{Secondary outcomes}

Data collection at 0 and 6 months will be used to perform test-retest reliability, to establish baseline reference measures and to assess for stability of outcome changes (24 months). Secondary child-focused and parent-focused outcomes will be compared at 0,6 and 12 months using Bonferroni corrections to account for multiple testing. All secondary service delivery and health system outcomes will be compared between the intervention and control as well.

\section{Additional analyses}

We will examine health system outcomes using regression modelling to explore the relationships between PROMs and health utilisation patterns (eg, the relationship of out-ofpocket expenditures with availability of home healthcare services).

\section{DISCUSSION}

While growing attention has been provided to CMC in recent years ${ }^{48}$ there are important gaps in the literature regarding the optimal care delivery model for CMC. ${ }^{17-19}{ }^{23}$ Before and after studies have shown possible benefit but there has been few rigorous RCTs conducted that look at multiple outcomes including service delivery, parent and child health outcomes as well as health system outcomes such as health utilisation. Furthermore, this is the first study that prioritised outcomes as identified by patients and families directly in order to understand if a complex care programme was successful in the eyes of a family by selecting outcomes that matter most to them. The care delivery model in CCKO-utilising a key worker and comprehensive care plans-is a time intensive and possibly costly one. Well-designed evaluations are needed to examine how they relate to outcomes of care for this population. ${ }^{49}$

Several aspects of this trial are important to highlight as innovative and novel.

First, in contrast to other trials that target CMC within a single healthcare setting (eg, a children's hospital), this study focuses on population-level implementation and evaluation in Ontario, Canada's most populous province. This setting allows the implementation of complex care coordination within a wide geographic area combing both densely populated urban areas with more rural locations for which travel to specialised care is challenging. The large number of sites participating in this study account for the majority of CMC care in Ontario. This environment is unique in terms of the current literature as these patients reflect population-level CMC representation, with outcome data availability across the continuum of care available from a large provincial repository of data. The focus on many sites creates some challenges in both implementation and evaluation across diverse settings. However, this evaluation also provides an opportunity for the development of generalisable knowledge not only for publically funded healthcare delivery systems but also for broad groups of payers focused on other high-need/high-cost populations. ${ }^{50}$

Second, the outcome measures used are patient and family informed. Previous literature has highlighted the need for uniquely developed outcome measures for $\mathrm{CMC}$ recognising the nature of their healthcare usage and trajectory. Before recruitment began, the outcome measures were determined through a process of direct consultation with parents of CMC. ${ }^{51}$ Previous evaluations of CMC care have relied primarily on readily available data (eg, claims data or other administrative datasets), with minimal patient and family reported input. Previous PROMs utilised in evaluations have not been validated in a CMC population. A strength of this study is the utilisation of broad outcomes that encompass multiple potential targets of care. We chose care coordination as the primary outcome measure because it is the primary target for change as in this patient population and the measurement instrument has been validated in CMC. Unfortunately, expectation of a change in disease status is not meaningful or realistic in many CMC, whereas improved navigation of the healthcare system is an important and improvable target of care. Biomedical endpoints, although important, are not meaningful in such a heterogeneous population.

Third, the study has been designed to mitigate risk of bias. It is anticipated that some patients may be excluded; a concern are those who are marginalised (eg, non-English speaking), or are deemed too urgent to enrol in a waitlist. 
We aim to conduct a secondary study focused on comparing such patients to contemporaneous controls using administrative data to ensure knowledge generation about the impact of CCKO in this group as well, although with a higher risk of bias that would otherwise be attenuated with randomization (eg, unmeasured confounders).

Fourth, the focus of this study is not solely quantitative in nature. We have elicited a mixed-methods approach. We will conduct interviews with a subset of intervention arm parents to capture their experience with the intervention, areas of improvement, as well as perceived benefits and harms. This approach will identify what aspects of the CCKO intervention are more or less effective, for whom, in what context and why.

Lastly, the integrated knowledge translation (KT) is unique in that the direct provincial implementation of the CCKO rollout has been matched directly with the evaluation such that the knowledge end-user was a part of the study team from the outset. The integrated KT approach has included families caring for CMC, policymakers and widely representative clinicians such as nurses and physicians. This large integrative model allows direct translation of results and seamless integration of knowledge.

\section{ETHICS AND DISSEMINATION}

The study research assistant will obtain informed consent from parental caregivers. Informed consent/assent will be obtained from all those who are able to provide it.

\section{Adverse event reporting}

While there are no adverse events expected, any adverse events will be reported to the research ethics board. All adverse events and adverse reactions will also be reported to the primary investigator within 24 hours.

\section{Dissemination}

CCKO represents a fully integrated knowledge transfer and exchange paradigm. The research team have worked with patient families and PCMCH to craft the provincial strategy, providing population-based data to understand the target population (numbers/location of children, patterns of care, health system costs). The committees overseeing implementation and evaluation encompass key knowledge users (patients, families, clinicians, administrators, policymakers), allowing for seamless KT. Executive summaries and/or presentations will be shared for wide dissemination to a variety of organisations/collaboratives. Academic KT will occur through presentation at academic conferences and publications in high-impact, peer-reviewed journals.

At study end, results will be available on CCKO's website.

\section{TRIAL STATUS}

Recruitment began January 2017 and there are 132 participants of a target of 140 as of February 2019. The study is on track to complete enrolment in 2019. A copy of the fulllength protocol is available on request .
Author affiliations

${ }^{1}$ Division of Pediatric Medicine, The Hospital for Sick Children, Toronto, Ontario, Canada

${ }^{2}$ Department of Pediatrics, University of Toronto, Toronto, Ontario, Canada ${ }^{3}$ Child Health Evaluative Sciences, The Hospital for Sick Children, Toronto, Ontario Canada

${ }^{4}$ School of Rehabilitation Therapy, Queen's University, Kingston, Ontario, Canada ${ }^{5}$ Institute of Health Policy, Management and Evaluation, University of Toronto Dalla Lana School of Public Health, Toronto, Ontario, Canada

${ }^{6}$ Department of Paediatrics, Children's Hospital of Eastern Ontario, Ottawa, Ontario, Canada

${ }^{7}$ Department of Pediatrics, Hamilton Health Sciences Center, McMaster University, Hamilton, Ontario, Canada

${ }^{8}$ Department of Pediatrics, Western University, London, Ontario, Canada

${ }^{9}$ Clinical Trials Unit, The Hospital for Sick Children, University of Toronto, Toronto, Ontario, Canada

${ }^{10}$ The Provincial Council for Maternal and Child Health, The Hospital for Sick Children, Toronto, Ontario, Canada

${ }^{11}$ Institute for Clinical Evaluative Sciences, Toronto, Ontario, Canada

${ }^{12}$ Department of Pediatrics, Royal Victoria Regional Health Centre, Barrie, Ontario, Canada

${ }^{13}$ Department of Pediatrics, North York General Hospital, University of Toronto, Toronto, Ontario, Canada

${ }^{14}$ The Credit Valley Hospital, Trillium Health Partners, Mississauga, Ontario, Canada

${ }^{15}$ Peterborough Regional Health Centre, Peterborough, Ontario, Canada

${ }^{16}$ Department of Pediatrics, Orillia Soldier's Memorial Hospital, Orillia, Ontario, Canada

${ }^{17}$ Department of Pediatrics, Michael Garron Hospital, Toronto, Ontario, Canada

Contributors $\mathrm{JO}$ and EC designed the study and the other authors (CYC, NF, JLLL, NM, AL, ERP, MEM, JS, RS, ARW, MO, AG, LB, RK, EC, KH-B, MG and MP) collaborated in the design of the study. EC and ARW provided statistical expertise. $\mathrm{JO}$ and CYC prepared the initial draft of the manuscript and EC revised the manuscript. All authors read, provided feedback, discussed and approved the final manuscript. All authors gave approval for the manuscript to be submitted.

Funding This study was funded by Canadian Institute of Health Research (Funding reference number: FDN-143315) and Ontario Strategy for PatientOriented Research Support Unit IMPACT (Innovative, Measurable, Patient-oriented, Appropriate, Collaborative andTransformative) Award.

Competing interests None declared.

Patient consent for publication Not required.

Ethics approval This study was approved by the local REB at: The Hospital for Sick Children (REB\# 1000053509), Hamilton Health Sciences (project \# 20172161), Children's Hospital of Eastern Ontario (ROMEO\# 20160299), London Health Sciences Center (project ID 108143), Michael Garron Hospital (REB\# 702-1701MNC-009), Credit Valley Hospital (ID\# 855), North York General Hospital (REB\# 16-0044), Royal Victoria Hospital (REB\# 015), Orillia Soldiers' Memorial Hospital and Peterborough Regional Health Centre.

Provenance and peer review Not commissioned; externally peer reviewed.

Open access This is an open access article distributed in accordance with the Creative Commons Attribution Non Commercial (CC BY-NC 4.0) license, which permits others to distribute, remix, adapt, build upon this work non-commercially, and license their derivative works on different terms, provided the original work is properly cited, appropriate credit is given, any changes made indicated, and the use is non-commercial. See: http://creativecommons.org/licenses/by-nc/4.0/.

\section{REFERENCES}

1. Wilson-Costello D, Friedman $\mathrm{H}$, Minich $\mathrm{N}$, et al. Improved survival rates with increased neurodevelopmental disability for extremely low birth weight infants in the 1990s. Pediatrics 2005;115(4):997-1003.

2. Tennant PW, Pearce MS, Bythell M, et al. 20-year survival of children born with congenital anomalies: a population-based study. Lancet 2010;375:649-56.

3. Plioplys AV. Survival rates of children with severe neurologic disabilities: a review. Semin Pediatr Neurol 2003;10:120-9.

4. Wise PH. The transformation of child health in the United States: social disparities in child health persist despite dramatic improvements in child health overall. Health Affairs 2004;23:9-25. 
5. Cohen E, Kuo DZ, Agrawal R, et al. Children with medical complexity: an emerging population for clinical and research initiatives. Pediatrics 2011;127:529-38.

6. Cohen E, Berry JG, Camacho X, et al. Patterns and costs of health care use of children with medical complexity. Pediatrics 2012;130:e1 463-e1470.

7. Simon TD, Berry J, Feudtner C, et al. Children with complex chronic conditions in inpatient hospital settings in the United States. Pediatrics 2010;126(4):647-55.

8. Berry JG, Hall M, Hall DE, et al. Inpatient growth and resource use in 28 children's hospitals: a longitudinal, multi-institutional study. JAMA Pediatr 2013;167:170-7.

9. Dosa NP, Boeing NM, Ms N, et al. Excess risk of severe acute illness in children with chronic health conditions. Pediatrics 2001;107:499-504.

10. Slonim AD, LaFleur BJ, Ahmed W, et al. Hospital-reported medical errors in children. Pediatrics 2003;111:617-21.

11. Matlow AG, Wright JG, Zimmerman B, et al. How can the principles of complexity science be applied to improve the coordination of care for complex pediatric patients? Qual Saf Health Care 2006;15:85-8.

12. Raina $P, O^{\prime}$ Donnell $M$, Rosenbaum $P$, et al. The health and well-being of caregivers of children with cerebral palsy. Pediatrics 2005;115:e62 6-e636.

13. Brehaut JC, Kohen DE, Garner RE, et al. Health among caregivers of children with health problems: findings from a Canadian populationbased study. Am J Public Health 2009;99:1254-62.

14. Sabbeth BF, Leventhal JM. Marital adjustment to chronic childhood illness: a critique of the literature. Pediatrics 1984;73:762-8.

15. Ratliffe CE, Harrigan RC, Haley J, et al. Stress in families with medically fragile children. Issues Compr Pediatr Nurs 2002;25:167-88.

16. Cohen E, Friedman JN, Mahant S, et al. The impact of a complex care clinic in a children's hospital. Child Care Health Dev 2010;36(4):574-82.

17. Cohen E, Lacombe-Duncan A, Spalding K, et al. Integrated complex care coordination for children with medical complexity: a mixedmethods evaluation of tertiary care-community collaboration. BMC Health Serv Res 2012;12:366.

18. Cohen E, Bruce-Barrett C, Kingsnorth S, et al. Integrated complex care model: lessons learned from inter-organizational partnership. Healthc Q 2011;14 Spec No 3:64-70.

19. Berry JG, Hall M, Neff J, et al. Children with medical complexity and Medicaid: spending and cost savings. Health Aff 2014;33:2199-206.

20. Farmer JE, Clark MJ, Drewel EH, et al. Consultative care coordination through the medical home for CSHCN: a randomized controlled trial. Matern Child Health J 2011;15:1110-8.

21. Looman WS, Antolick M, Cady RG, et al. Effects of a Telehealth Care Coordination Intervention on Perceptions of Health Care by Caregivers of Children With Medical Complexity: A Randomized Controlled Trial. J Pediatr Health Care 2015;29:352-63.

22. McKissick HD, Cady RG, Looman WS, et al. The Impact of Telehealth and Care Coordination on the Number and Type of Clinical Visits for Children With Medical Complexity. J Pediatr Health Care 2017;31:452-8.

23. Cohen E, Jovcevska V, Kuo DZ, et al. Hospital-based comprehensive care programs for children with special health care needs: a systematic review. Arch Pediatr Adolesc Med 2011;165:554-61.

24. Mosquera RA, Avritscher EB, Samuels CL, et al. Effect of an enhanced medical home on serious illness and cost of care among high-risk children with chronic illness: a randomized clinical trial. JAMA 2014;312:2640-8.

25. Simon TD, Whitlock KB, Haaland W, et al. Effectiveness of a Comprehensive Case Management Service for Children With Medical Complexity. Pediatrics 2017;140(6):e20171641.

26. Gresley-Jones T, Green P, Wade S, et al. Inspiring Change: How a Nurse Practitioner-Led Model of Care Can Improve Access and Quality of Care for Children With Medical Complexity. J Pediatr Health Care 2015;29:478-83.

27. Adams S, Mahant S, Cohen E. Comprehensive care for medically complex children: The pediatric nurse practitioner - pediatric hospitalist model of collaborative care. Hospital Pediatrics 2009:20-2.
28. Hussey MA, Hughes JP. Design and analysis of stepped wedge cluster randomized trials. Contemp Clin Trials 2007;28:182-91.

29. Brown CA, Lilford RJ. The stepped wedge trial design: a systematic review. BMC Med Res Methodol 2006;6:54.

30. Provincial Council of Maternal and Child Health. CCKO Standard Operational Definition CMC-MFTD. 2015 http://www.pcmch.on.ca/ resource/ccko-operational-definition/pcmch-standard-operationaldefinition-cmc-mftd_ac-edits-v2-2/ (accessed 04 Apr 2018).

31. McDonald KM SV, Bravata DM, Lewis R, et al. Closing the Quality Gap: A Critical Analysis of Quality Improvement Strategies. Rockville, MD: Stanford University-UCSF Evidence-based Practice Center, 2007

32. Provincial Council of Maternal and Child Health. Complex Care for Kids Ontario http://www.pcmch.on.ca/health-care-providers/ paediatric-care/complex-care-kids-ontario/.

33. Fayed N, Gardecki M, Cohen E; Complex Care for Kids Ontario evaluation team. Partnering with families of children with medical complexity to evaluate interventions. CMAJ 2018;190(Suppl):S24 $-\mathrm{S} 25$.

34. Gidengil C, Parast L, Burkhart Q, et al. Development and Implementation of the Family Experiences With Coordination of Care Survey Quality Measures. Acad Pediatr 2017;17:863-70.

35. Parast L, Burkhart Q, Gidengil C, et al. Validation of New Care Coordination Quality Measures for Children with Medical Complexity. Acad Pediatr 2018;18:581-8.

36. Mangione-Smith R. Family Experiences with Care Coordination measure set (FECC). 2015 https://www.seattlechildrens.org/research/ centers-programs/child-health-behavior-and-development/labs/ mangione-smith-lab/measurement-tools/.

37. World Health Organization. Constitution of WHO: principles, 2016.

38. Ravens-Sieberer U, Gosch A, Rajmil L, et al. KIDSCREEN-52 quality-of-life measure for children and adolescents. Expert Rev Pharmacoecon Outcomes Res 2005;5:353-64.

39. Fayed N, de Camargo OK, Kerr E, et al. Generic patient-reported outcomes in child health research: a review of conceptual content using World Health Organization definitions. Dev Med Child Neurol 2012;54:1085-95.

40. Brand K, Court C. Pain assessment in children. Anaesth Intensive Care Med 2010;11:214-6.

41. McGrath PA. An assessment of children's pain: a review of behavioral, physiological and direct scaling techniques. Pain 1987;31:147-76.

42. Diener E. Subjective well-being. The science of happiness and a proposal for a national index. Am Psychol 2000;55:34-43.

43. Diener E, Emmons RA, Larsen RJ, et al. The Satisfaction With Life Scale. J Pers Assess 1985;49:71-5.

44. Cella D, Yount S, Rothrock N, et al. The Patient-Reported Outcomes Measurement Information System (PROMIS): progress of an NIH Roadmap cooperative group during its first two years. Med Care 2007;45:S3-s11.

45. Lai JS, Stucky BD, Thissen D, et al. Development and psychometric properties of the PROMIS $(\circledR)$ pediatric fatigue item banks. Qual Life Res 2013;22:2417-27.

46. Jaeschke R, Singer J, Guyatt GH. Measurement of health status. Ascertaining the minimal clinically important difference. Control Clin Trials 1989;10:407-15

47. Harris PA, Taylor R, Thielke R, et al. Research electronic data capture (REDCap)--a metadata-driven methodology and workflow process for providing translational research informatics support. $J$ Biomed Inform 2009;42:377-81.

48. Cohen E, Berry JG, Sanders L, et al. Status Complexicus? The Emergence of Pediatric Complex Care. Pediatrics 2018;141(Suppl 3):S202-S211.

49. Lion KC, Mangione-Smith R, Britto MT. Individualized plans of care to improve outcomes among children and adults with chronic illness: a systematic review. Care Manag J 2014;15:11-25.

50. Hochman M, Asch SM. Disruptive Models in Primary Care: Caring for High-Needs, High-Cost Populations. J Gen Intern Med 2017;32:392-7.

51. Barnert ES, Coller RJ, Nelson BB, et al. Experts' Perspectives Toward a Population Health Approach for Children With Medical Complexity. Acad Pediatr 2017;17:672-7. 
Correction: Complex care for kids Ontario: protocol for a mixed-methods randomised controlled trial of a populationlevel care coordination initiative for children with medical complexity

Orkin J, Chan CY, Fayed N, et al. Complex care for kids Ontario: protocol for a mixedmethods randomised controlled trial of a population-level care coordination initiative for children with medical complexity. BMJ Open 2019;9:e028121. doi: 10.1136/ bmjopen-2018-028121.

This article was previously published with errors in data.

- In the 'Primary outcome' section, there's a typo: it says "as they hadve content relation to:"; it should instead read "as they have content relation to:"

- In the 'Sample size' section,

- The last sentence in the first paragraph is missing the second part. It should read: 'projected smallest clinically important difference of 0.5 of the within-patient SD, which is recommended by the developer as a moderate effect size.'

- The second paragraph should start with 'The required sample size is considered feasible as it is estimated that a pool of about 250 patients are readily identifiable for recruitment at CCKO sites.'

Open access This is an open access article distributed in accordance with the Creative Commons Attribution Non Commercial (CC BY-NC 4.0) license, which permits others to distribute, remix, adapt, build upon this work non-commercially, and license their derivative works on different terms, provided the original work is properly cited, appropriate credit is given, any changes made indicated, and the use is non-commercial. See: http://creativecommons.org/licenses/by-nc/4.0/.

C Author(s) (or their employer(s)) 2019. Re-use permitted under CC BY-NC. No commercial re-use. See rights and permissions. Published by BMJ.

BMJ Open 2019;9:e028121corr1. doi:10.1136/bmjopen-2018-028121corr1

(D) Check for updates 